\title{
Operative treatment of ipsilateral fracture distal radius and scaphoid
}

\begin{abstract}
Background: The purpose of this study was to evaluate the results of operative treatment in patients with ipsilateral fractures of the distal radius and scaphoid.

Between 2010 to 2014 , seven patients were treated operatively for ipsilateral injuries involving distal end radius and scaphoid. Percutanous fixation of all scaphoid fractures was done first, using cannulated Herbert screw and fracture distal end radius was treated by open reduction and plate fixation.All fractures were united without any secondary procedures. The mean follow-up was 24.5 months. Functionally 6 patients had excellent,and one had good outcome according to the demerit point system of Gartland and Werley.
\end{abstract}

Conclusion: In spite of the small sample size due to rare nature of the injury, we can recommend Radial fracture be treated as one would treat an isolated injury on basis of fracture pattern, in addition percutanous fixation of scaphoid fracture.
Volume 8 Issue 4 - 2017

Mohamed A Samy

Department of orthopaedic, Menofyia University, Egypt

Correspondence: Mohamed A Samy, MD (ortho), FRCS

(Dublin), Lecturer of orthopaedic surgery, Menofyia university,

Shebin Elkoum-Menofyia, Egypt, Email mrmsamy@hotmail.com

Received: May 16, 2017| Published: July 07, 2017

Keywords: Scaphoid, Herbert screw, Distal radius

\section{Background}

Ipsilateral fractures of the distal radius and scaphoid are rare injury. The reported frequency has varied from $0.7 \%$ to $6.5 \%$ in cases of isolated fractures of each bone..$^{1-3}$ The mechanism by which the injury occurs is usually that of a rapid forced loading of the outstretched and hyperextended ulnar deviated and pronated wrist. ${ }^{4}$ The distal radius fracture is often intra-articular, while the scaphoid fracture occurs at the waist in most cases. Some authors have suggested that cast or splint immobilization is adequate for scaphoid fractures, ${ }^{3,5}$ while others have suggested that fixation of the scaphoid before reduction of the distal radius is needed to prevent distraction of the scaphoid, which may induce nonunion. ${ }^{4,6}$

The purpose of this study was to evaluate the results of operative treatment of ipsilateral fractures of the distal radius and scaphoid.

\section{Patients and methods}

Between March 2010 to November 2014, seven patients were treated operatively for ipsilateral injuries involving distal end radius and scaphoid. The patients' ages averaged 31.1 years (range, 22 to 40). The dominant hand (right) was the injuried hand in 6 patients, all patients were males.

Distal radius fractures were classified according to Muller comprehensive classification of fractures, ${ }^{7}$ all were displaced intraarticular. All scaphoid fractures were undisplaced or $\leq 2 \mathrm{~mm}$ and localized in the middle third with no rotational subluxation or carpal instability. CT-scan was done preoperatively for all patients to assess mainly the morphology of radius fracture. The average time between injury and surgical interference was 2.5 days, (range 2-3). Percutanous fixation of all scaphoid fractures was done first, using cannulated Herbert screw inserted volar from distal to proximal under C- arm guide.Then, open reduction and internal fixation by fragment specific plate for lower end radius was done for all.

Transfixing percutanous $\mathrm{K}$ wire and above elbow splint in supination was done in one patient who had inferior radioulnar dorsal subluxation and removed by 5 th week, other patients were allowed to start gentle exercise as early as possible with the use of removable wrist splint.

All patients were regularly followed up every week in the clinic during first month,then every 2-3 weeks in the next five months after, and every eight weeks till the end of follow up. Radiological imaging was done every 3 weeks till fracture healing, then lastelly at the end of follow up. Functional evaluation of the patients was done at the last follow up according to the demerit point system of Gartland and Werley. ${ }^{8}$

This system is based on a demerit point system which involves an objective evaluation of wrist function. It relies on the concept that a minimum of $45^{\circ}$ dorsiflexion, $30^{\circ}$ palmar flexion, $15^{\circ}$ ulnar and radial deviation and $50^{\circ}$ pronation and supination is being the minimum for normal function. Hand grip strength was assessed as percentage of the contra lateral side.

\section{Results}

The mean duration of follow-up was24.5 months(range 18-33). All fractures were united without any secondary procedures, the average healing of scaphoid was 13.2weeks(range12-15), that of lower end radius was 6.7weeks (range 6-8). No patient had soft tissue infection,tendon or nerve irritation. At the end of follow up the average hand grip strength was $84.8 \%$ of the contralateral side (range $89 \%-75 \%$ ), all the patients were satisfied and returned to their normal avtivities. According to the Sarmiento "es modification of Lind Strom Criteria ${ }^{9}$ all patients had grade 1 restoration of anatomy.Function scoring was done according to the demerit point system of Gartland and Werley, ${ }^{8} 6$ patients had excellent,and one had good outcome (Table 1 \& Figure1).

\section{Discussion}

Ipsilateral fracture of the distal radius and scaphoid is very uncommon. The reported age distribution for this combined injury is mainly from the third to the fifth decade. ${ }^{3}$ Our series had age distribution, which was mainly from 22 to 40 years old. 
Table I Patient's Data

\begin{tabular}{|c|c|c|c|c|c|c|c|c|c|c|}
\hline \multirow{2}{*}{$\begin{array}{c}\text { Age } \\
\text { NYears }\end{array}$} & \multirow{2}{*}{ Side } & \multirow{2}{*}{$\begin{array}{l}\text { Radius } \\
\text { union } \\
\text { (Weeks) }\end{array}$} & \multirow{2}{*}{$\begin{array}{l}\text { Scaphoid } \\
\text { Union } \\
\text { (Weeks) }\end{array}$} & \multirow[b]{2}{*}{ Associated injuries } & \multicolumn{3}{|l|}{ F/U } & \multicolumn{3}{|c|}{ Wrist Wrist } \\
\hline & & & & & (M) & Wrist flexion ${ }^{\circ}$ & Wrist extension ${ }^{\circ}$ & UD & $\mathbf{R D}^{\circ}$ & prosup \\
\hline 131 & $\mathrm{R}$ & 7 & 13 & $\mathrm{fx}$ calcanous & 30 & 60 & 60 & 25 & 15 & 6560 \\
\hline 224 & $\mathrm{~L}$ & 6 & 14 & IRUS & 18 & 60 & 55 & 20 & 20 & 6065 \\
\hline 340 & $\mathrm{R}$ & 8 & 15 & fXUST & 33 & 70 & 70 & 25 & 20 & 6070 \\
\hline 436 & $\mathrm{R}$ & 7 & 14 & fxUST & 24 & 60 & 70 & 25 & 15 & 6575 \\
\hline 537 & $\mathrm{R}$ & 7 & 13 & & 19 & 65 & 60 & 20 & 15 & $65 \quad 65$ \\
\hline 628 & $\mathrm{R}$ & 6 & 12 & & 20 & 70 & 65 & 20 & 20 & 6070 \\
\hline 722 & $\mathrm{R}$ & 6 & 12 & & 28 & 70 & 60 & 25 & 15 & $60 \quad 65$ \\
\hline
\end{tabular}

R: Right; L: Left; Fx: Fracture; IRUS: Inferior Radioulnar Subluxation; Fxust: Fracture Ulnar Styloid Process; M: Months; UD: Range Of Ulnar Deviation; RD: Range of Radial Deviation; Pro: Range Of Pronation; Sup: Range of Supination
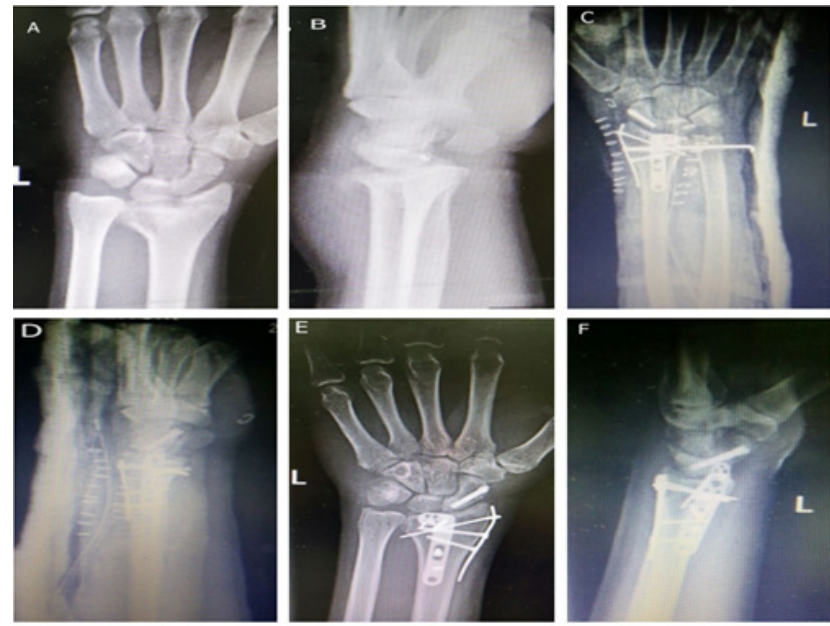

Figure I $\mathrm{N}=57$; Epidemiological distribution of the pathological fractures, traumatic fractures, and nonunion.

There is some controversy about the mechanism of this type of combined injury.Frykman used experimental methods to show that the distal radius fracture occurs first, followed by the scaphoid fracture. ${ }^{10}$ However, Stother, ${ }^{11}$ Mayfield, ${ }^{12}$ and Moller ${ }^{13}$ suggested that under high-energy insult, the scaphoid fracture occurs first and then continued axial loading and extension of the wrist produce the fracture of the radius.

In our series, all scaphoid fractures were non-displaced or $\leq 2 \mathrm{~mm}$ waist fractures. While the fractures of the distal radius had varied intra-articular extension. It seemed that the radius had absorbed the majority of the energy, then the residual energy produced a scaphoid fracture. Many authors ${ }^{1,3,5,11}$ believe that, in most instances, the scaphoid fracture is non-displaced and, thus, stable union is almost always certain, and reduction of the scaphoid will not be lost even with traction forces across the wrist.

In our opinion; This period of immobilization (3-4months) for the treatment of scaphoid fracture, at best, results in delay in recovery of hand and wrist function and, at worst, permanent stiffness. Also scaphoid fixation ensures no distraction at the fracture site during reduction of the radius. In our study, although all fractures of scaphoid were undisplaced, percutanous fixation with cannulated Herbert screw was done for all patients. Rutgers et al. ${ }^{14}$ had supported our opinion of percutanous scaphoid fixation in such combined injury even undisplaced one.

Six of our patients had excellent and one had good function outcome.
Oskam et al., ${ }^{5}$ indicated that distal radius fracture is the principal injury that determines the outcome of treatment.

\section{Conclusion}

In spite of the small sample size, this is a rare injury and a large series is difficult to attain but we can recommend that ; Radial fracture be treated as one would treat an isolated injury on basis of fracture pattern,in addition percutanous fixation of scaphoid fracture provides a stable fixation that resists bending,rotational,and shear forces, and early joint motion.

\section{Conflicts of Interest}

Authors no interest, any financial gains, or relationship to any third party relating to this study.

\section{Ethical Standards}

This study complies with the current laws of the country in which it was conducted.

\section{Acknowledgments}

None.

\section{References}

1. Tountas AA, Waddell JP. Simultaneous fractures of the distal radius and scaphoid. J Orthop Trauma. 1987;1(4):312-317.

2. Smith JT, Keeve JP, Bertin KC, et al. Simultaneous fractures of the distal radius and scaphoid. $J$ Trauma. 1988;28(5):676-679.

3. Hove LM. Simultaneous scaphoid and distal radial fractures. $J$ Hand Surg Br. 1994;19(3):384-387.

4. Trumble TE, Benirschke SK, Vedder NB. Ipsilateral fractures of the scaphoid and radius. J Hand Surg Am. 1993;18(1):8-14.

5. Oskam J, Graaf JSD, Klasen HJ. Fractures of the distal radius and scaphoid. J Hand Surg Br. 1996;21(6):772-774.

6. Richards RR, Ghose T, McBroom RJ. Ipsilateral fractures of the distal radius and scaphoid treated by Herbert screw and external skeletal fixation. Clin Orthop Relat Res. 1992;(282):219-221.

7. Muller ME, Nazarian S, Koch P. AO classification of fractures, Berlin, Springer, Germany. 1987.

8. Gartland JJ, Werley CW. Evaluation of healed Colles' fracture. J Bone Joint Surg Am. 1951;33A(4):895-907.

9. Sarmiento A, Pratt GW, Berry NC, et al. Colles' fractures. Functional bracing in supination. J Bone Joint Surg Am. 1975;57(3):311-317. 
10. Frykman G. Fracture of the distal radius including sequelae:shoulderhand-finger syndrome, disturbance of the distal radio-ulnar joint and impairment of nerve function. A clinical and experimental study. Acta Orthop Scand. 1967;108(suppl):3.

11. Stother JG. A report of three cases of simultaneous Colles and scaphoid fractures. Injury. 1975;7(3):185-188.
12. Mayfield JK. Mechanism of carpal injuries. Clin Orthop Relat Res. 1980;(149):45-54

13. Moller BN. Simultaneous fracture of the carpal scaphoid and adjacent bones. Hand. 1983;15(3):258-261.

14. Rutgers M, Mudgal CS, Shin R. Combined fractures of the distal radius and scaphoid. Journal of Hand Surgery. 2008;33(4):478-483. 